\title{
ArcheoSciences
}

Revue d'archéométrie

33 (suppl.) | 2009

Mémoire du sol, espace des hommes

\section{Tumuli exploration using surface 3D Electrical Resistivity Tomography}

Nikos G. Papadopoulos, Myeong-Jong Yi, Jung-Ho Kim, Gregory N.

Tsokas, Panagiotis Tsourlos and Apostolos Sarris

\section{OpenEdition}

\section{Electronic version}

URL: https://journals.openedition.org/archeosciences/1430

DOI: $10.4000 /$ archeosciences. 1430

ISBN: 978-2-7535-1599-4

ISSN: $2104-3728$

Publisher

Presses universitaires de Rennes

\section{Printed version}

Date of publication: 30 October 2009

Number of pages: $129-132$

ISBN: 978-2-7535-0943-6

ISSN: 1960-1360

\section{Electronic reference}

Nikos G. Papadopoulos, Myeong-Jong Yi, Jung-Ho Kim, Gregory N. Tsokas, Panagiotis Tsourlos and Apostolos Sarris, "Tumuli exploration using surface 3D Electrical Resistivity Tomography",

ArcheoSciences [Online], 33 (suppl.) | 2009, Online since 30 October 2011, connection on 01 February

2022. URL: http://journals.openedition.org/archeosciences/1430 ; DOI: https://doi.org/10.4000/ archeosciences. 1430 


\title{
Tumuli exploration using surface 3D Electrical Resistivity Tomography
}

\author{
Nikos G. Papadopoulos*, Myeong-Jong YI*, Jung-Ho Kim*, Gregory Tsokas **, \\ Panagiotis Tsourlos ** and Apostolos SARrIs ${ }^{* * *}$
}

Key words: Tumuli, Models, 3D inversion, Archaeological site, Greece.

\section{INTRODUCTION}

The direct current resistivity method is nowadays a well established geophysical technique, used routinely and successfully in the detection and mapping of concealed subsurface structures, like walls, ditches and anthropogenic or natural cavities (Dahlin and Zhou, 2004). In archaeological geophysics, tombs constitute the most common subterranean manmade cavities of the greatest archaeological and historical importance. Several successful case studies in the detection of tombs have been reported, mainly where the investigated area is almost flat or with relatively small topographic variation. (Nyari and Kanli, 2007).

The detection of tombs inside tumuli constitutes an interesting problem (Tsokas et al., 1995; Vafidis et al., 1995). The tumuli are small artificial hills that cover tombs, usually monumental ones, and perhaps other archaeological structures. Their architectural significance is comparable to the archaeological importance of their content. In fact, tumuli are by themselves monuments of past human activity and offer opportunities to reconstruct important information about the life and customs of the building period.

The non-invasive exploration of tumuli is a challenging geophysical problem. The three-dimensional shape, the abrupt topographical variation and the heteroge- neous materials of the tumulus must be taken into special consideration for its successful geophysical investigation (Tsokas and Rocca, 1987). In this work, the surface three dimensional (3D) Electrical Resistivity Tomography (ERT) method was considered, in order to investigate the properties of the tumulus filling material. Different electrode arrays were tested. The method's ability to record buried archaeological structures inside the tumulus, like tombs, is also explored.

The applicability of the 3D ERT method to the reconstruction of tumulus filling material and subsurface structures is approached by numerical modeling and $3 \mathrm{D}$ inversion of synthetic apparent resistivity data. The uneven terrain of a tumulus is simulated by a capsized cup topography model having a maximum diameter of $20 \mathrm{~m}$ and height of $4 \mathrm{~m}$ (Fig. 1b). The filling material of the tumulus consists of two layers with different geoelectrical properties $(150 \mathrm{ohm}-\mathrm{m}$ and $100 \mathrm{ohm}-\mathrm{m}$ respectively) in order to consider the vertical non-homogeneity inside the tumulus due to the different layers of soil, sand and gravels. Furthermore, the horizontal non-homogeneity caused by contact of natural soil and the artificial tumulus material was simulated by assigning the value of $50 \mathrm{ohm}-\mathrm{m}$ to the background. The tombs covered by the tumulus were represented by two highly resistive bodies located one at the periphery (dimensions $2 \times 2 \times 1 \mathrm{~m}$ )

\footnotetext{
* Korea Institute of Geoscience and Mineral Resources (KIGAM), Mineral Resources Research Division, Laboratory of Resource Exploration Development, 92 Gwahang-no, Yuseong-gu, Daejeon, 305-350, S. Korea. (nikos@ims.forth.gr)

** Department of Geophysics, School of Geology, Aristotle University of Thessaloniki, 54124, Thessaloniki, Greece.

*** Laboratory of Geophysical-Satellite Remote Sensing \& Archaeo-environment, IMS-FORTH Rethymnon, Greece.
} 


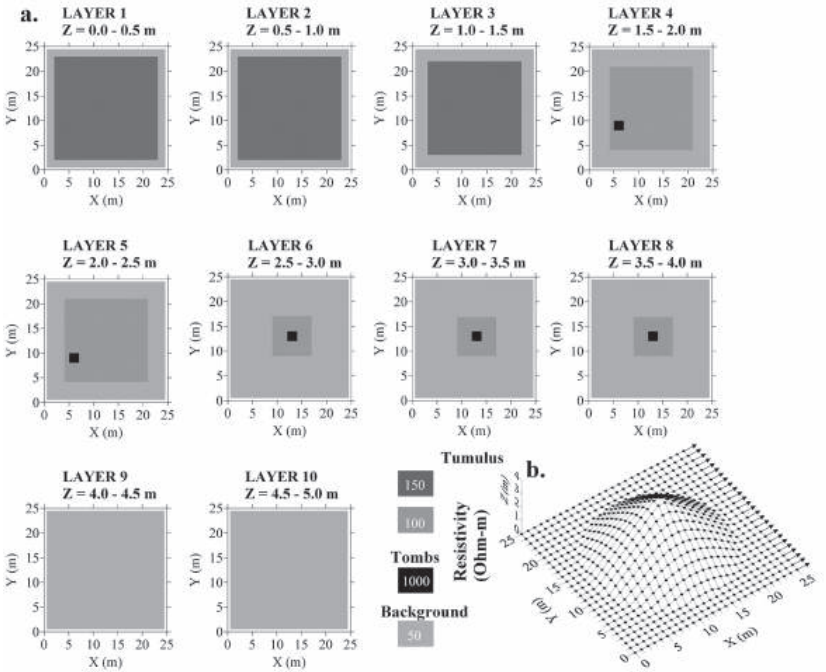

Figure 1 (see color plate): a) 3D resistivity model used to simulate the filling material and the tombs that are concealed inside a tumulus. b) Capsized cup topography model used to simulate the three dimensional shape of a tumulus. The solid lines with the arrows along the $\mathrm{X}$-axis show the direction of each one of the $2 \mathrm{D}$ lines used to collect the data. The black dots indicate the surface position (X, Y, Z coordinates) of the electrodes which were placed along each individual 2D line.

and the other below the center (dimensions $2 \times 2 \times 1.5 \mathrm{~m}$ ) of the tumulus (Fig. 1a).

A surface resistivity survey composed of 26 parallel two dimensional (2D) traverses along the $\mathrm{X}$ direction was simulated. The inter-line and the basic unit electrode distances were both set equal to $1 \mathrm{~m}$ (Fig. 1b). The resolution capabilities of this specific survey strategy approach those of a complete 3D survey and can maximize the detailed 3D mapping of buried archaeological structures (Papadopoulos et al., 2007). A unique elevation value was assessed for each of the electrodes used to cover the whole area of interest. The Dipole-Dipole (DD), Pole-Dipole (PD), Pole-Pole (PP) and Gradient (GRAD) arrays, which are suitable for multichannel resistivity instruments, were tested. An effort was made to keep similar acquisition parameters for all the arrays for direct comparison of the final inversion models.

\section{Synthetic 3D Modeling AND InVERSION}

A 3D Finite Element algorithm with distorted mesh which was consistent with the tumulus uneven terrain was used to calculate the response of the original model. In order to simulate field conditions, the synthetic potential difference data were contaminated with random electrical noise of $1 \mathrm{mV} / \mathrm{A}$ peak-to-peak amplitude (Yi et al., 2001). The 3D resistivity model was described by ten parameter layers of constant thickness equal to $0.5 \mathrm{~m}$. The inversion procedure was based on a smoothness-constrained Gauss-Newton algorithm. The Active Constraint Balancing (ACB) method was also applied in order to enhance the least-squares resolving power and stability (Yi et al., 2001). The effect of tumulus topography was also incorporated in the $3 \mathrm{D}$ inversion procedure.

The synthetic modeling approach showed that vertical non-homogeneity due to the different layers inside the tumulus was identified by all the tested arrays with compa-

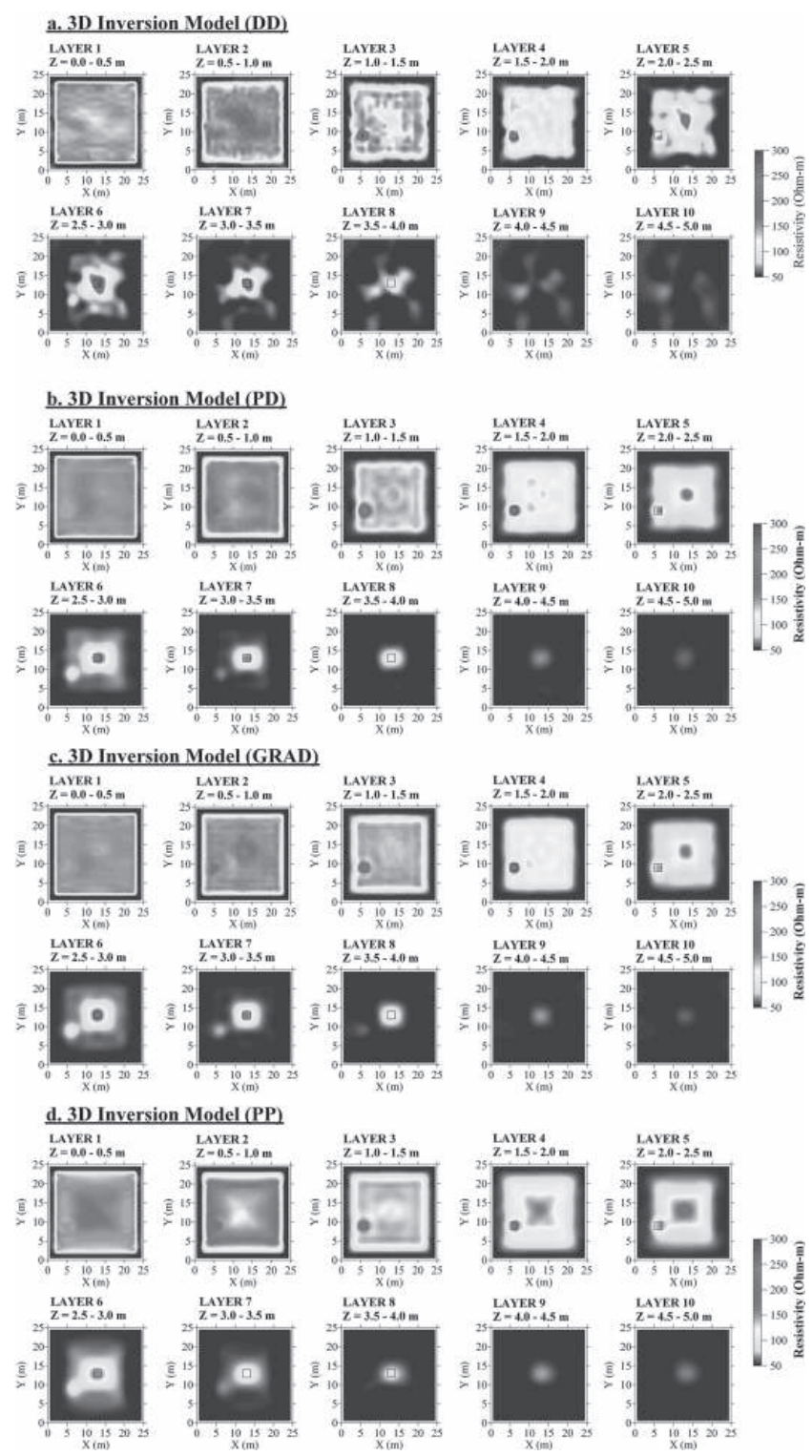

Figure 2 (see color plate): 3D resistivity inversion models for the a) Dipole-Dipole (DD) b) Pole-Dipole (PD) c) Gradient (GRAD) and d) Pole-Pole (PP) arrays. 
rable accuracy. The horizontal non-homogeneity between the undisturbed soil and the tumulus artificial material was also reconstructed by all the inversion models (Fig. 2).

Concerning the concealed tombs, the PD array gave a comparatively more resolvable inversion model in relation to the other arrays (Fig. 2b). The horizontal dimensions and the location of the tombs were reconstructed with great accuracy. On the other hand, the top of the tomb located at the periphery was underestimated by the inversion and the central tomb was slightly shifted upwards in the vertical direction. These inversion artifacts can be attributed to the uneven topography and the inability of the Finite Element Mesh to accurately represent the steep topographical variations of the tumulus.

The DD, PD and GRAD arrays seem to have comparable investigation depths. The GRAD model is of comparable accuracy with the PD one indicating that the gradient array can be a strong alternative for a 3D resistivity survey (Fig. 2c). On the other hand the DD array (Fig. 2a) resulted in a more distorted model with less resolution. This is probably caused by the amount of noise, the specific electrode geometry used for the DD and the low signal to noise $(\mathrm{S} / \mathrm{N})$ of this specific array. The inherent low resolution of the PP array (Fig. 2d) comprises the main reason of the low resolution of the final inversion model of this array.

\section{Real Data}

In order to provide a ground truthing of the above results, a total of thirty eight parallel $2 \mathrm{D}$ pole-dipole lines along a single survey direction were measured in order to investigate a small tumulus in the archaeological site of Aegae (Vergina, Macedonia, North Greece). The tumulus covers an area of $22.2 \times 19.2 \mathrm{~m}$ and its maximum height is $4 \mathrm{~m}$. The interline distance and inter-electrode distance was $0.6 \mathrm{~m}$. The $3 \mathrm{D}$ resistivity inversion algorithm managed to reconstruct a model which describes to a certain degree the properties of the tumulus filling material and the basic archaeological structures concealed inside. The high resistivity anomalies A, $\mathrm{B}, \mathrm{C}, \mathrm{D}$ and $\mathrm{E}$ are present at different depths and therefore exhibit the highest possibility to indicate buried archaeological features. These results will guide the excavation of the tumulus.

The main aim of this work is to provide an initial insight for collecting and processing 3D surface ERT data for optimum mapping of tumulus properties. In this respect, it is shown that the PD and the GRAD arrays comprise the optimum choices for investigating a tumulus. The dense grid of parallel 2D ERTs collected from a small tumulus in northern Greece contributed to locating high resistivity features which are probably small buried graves.
Figure 3 (see color plate): Resistivity inversion model of the Vergina data along with the diagrammatic interpretation of the high resistivity anomalies which are probably caused by archaeological structures buried in the tumulus subsurface.
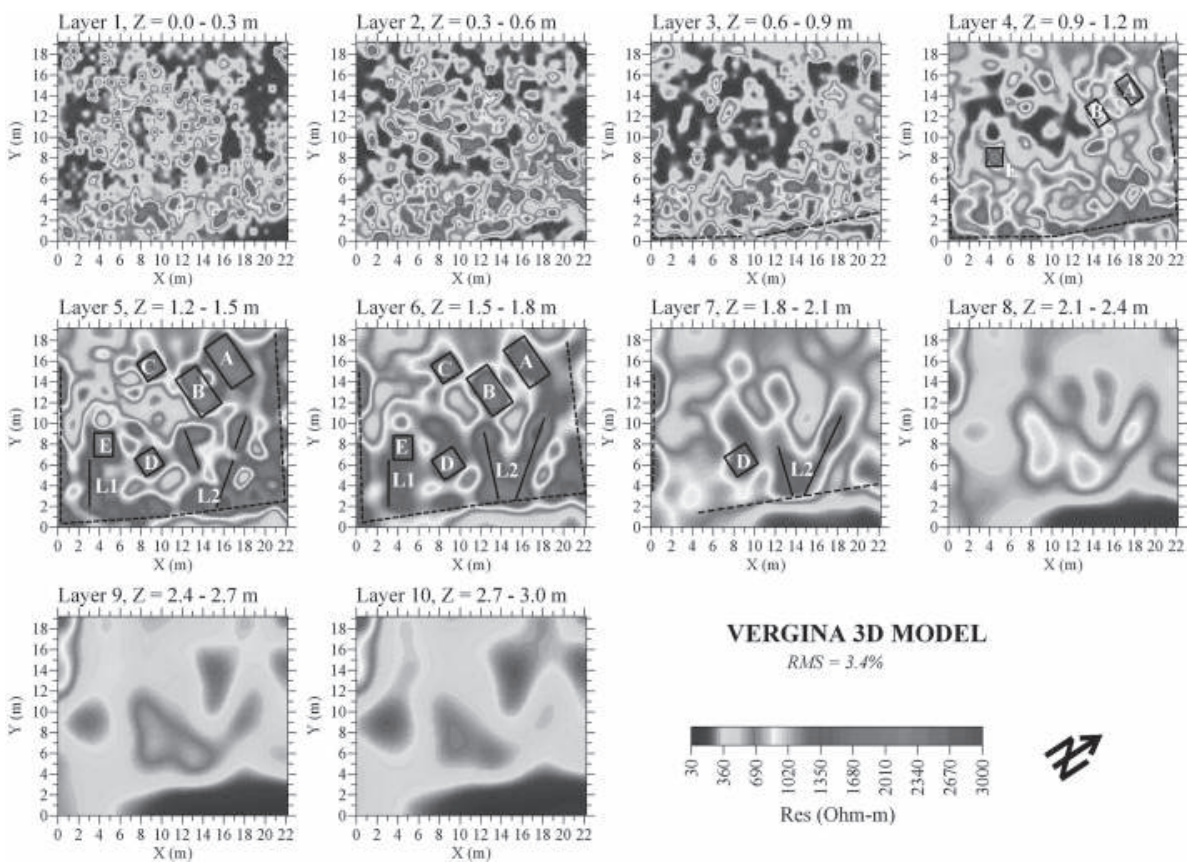

VERGINA 3D MODEL

$$
\text { RMS }=3.4 \%
$$
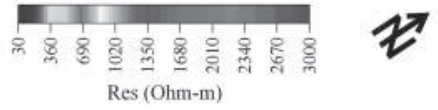


\section{Acknowledgements}

This research work was supported by the Basic Research Project of the Korea Institute of Geoscience and Mineral Resources funded by the Ministry of Knowledge Economy of Korea.

\section{References}

Dahlin, T. and Zhou, B., 2004. A numerical comparison of 2D resistivity imaging with 10 electrode arrays. Geophysical Prospecting, 52: 379-398.

Nyari, Z. and KANLI, A. I., 2007. Imaging of Buried 3D Objects by using Electrical Profiling Methods with GPR and 3D Geoelectrical Measurements. J. Geophys. Eng., 4: 83-93.

Papadopoulos, N. G., Tsourlos, P., Tsokas, G. N. and Sarris, A., 2007. Efficient ERT Measuring and Inversion Strategies for 3D Imaging of Buried Antiquities. Near Surface Geophysics, 5: 349-362.
Tsokas, G. N. and RoccA, A. C., 1987. Field investigation of a Macedonian Tumulus by resistivity soundings. Geoexploration, 24: 99-108.

Tsokas, G. N, Papazachos, C. B., Vafidis, A., Loukoyiannakis, M., Vargemezis, G. and Tzimeas, K., 1995. The detection of monumental tombs in tumuli by refraction seismics. Geophysics, 60:1735-1742.

Vafidis, A., Tsokas, G. N., Loukoyiannakis, M. Z., Vasiliadis, K., Papazachos, C. B. and Vargemezis, G., 1995. Feasibility Study on the Use of Seismic Methods in Detecting Monumental Tombs Buried in Tumuli. Archaeological Prospection, 2: 119128.

Yı, M.-J., KIM, J.-H., Song, Y., Cho, S.-J., Chung, S.-H. and SuH, J.-H., 2001. Three-Dimensional Imaging of Subsurface Structures using Resistivity Data. Geophysical Prospecting, 49: 483-497. 